\title{
Automated speed enforcement systems to reduce traffic-related injuries: closing the policy implementation gap
}

\author{
Stephanie R Morain, ${ }^{1}$ Andrea C Gielen, ${ }^{2}$ Kavi Bhalla ${ }^{3}$
}

In the USA, traffic-related injuries are responsible for over 33000 deaths each year ${ }^{1}$ and are the leading cause of death for individuals aged 1-24 years. $^{2}$ Traffic-related injuries also take a substantial economic toll, accounting for over $\$ 99$ billion annually in medical costs and associated productivity losses. ${ }^{3}$ Globally, $>1.3$ million people are killed each year by traffic-related injuries, and an additional 78.2 million sustain nonfatal injuries warranting medical care. ${ }^{4}$

Controlling speed is an important means for preventing traffic-related injuries. Speed is a 'two-pronged aggravator' of injuries, correlated both to crash likelihood and to severity. ${ }^{5}$ Speed is estimated to be a factor in over $30 \%$ of fatal crashes in the USA, resulting in over 10000 annual fatalities. ${ }^{1}$ Enforcement of speed limits has been repeatedly demonstrated to reduce the frequency and severity of motor vehicle crashes (MVCs). ${ }^{6} 7$ Speed enforcement can also have positive environmental impacts, reducing fuel consumption and resultant emissions. ${ }^{7}$

How best to enforce speed limits remains an open question. In the USA, the most common method of speed enforcement relies upon police officers using radar technologies installed in vehicles to detect speeding drivers and issue citations at the time of the offense. However, several features of traditional enforcement limit its effectiveness. As Delaney et $a l^{8}$ note, traditional enforcement is 'resource intensive and inconsistent in its application.' This inconsistency reduces effectiveness, while introducing concerns for biased enforcement, including the potential for racial profiling in traffic stops. ${ }^{9}$ Drivers may also evade traditional enforcement by reducing speed only in areas

\footnotetext{
${ }^{1}$ Berman Institute of Bioethics, Johns Hopkins University, Baltimore, Maryland, USA; ${ }^{2}$ Johns Hopkins Center for Injury Research and Policy, Johns Hopkins School of Public Health, Baltimore, Maryland, USA; ${ }^{3}$ Johns Hopkins International Injury Research Unit, Johns Hopkins School of Public Health, Baltimore, Baltimore, USA

Correspondence to Dr Stephanie R Morain, Berman Institute of Bioethics, Johns Hopkins University, 1809 Ashland Ave, Baltimore, MD 21205, USA; smorain1@jhu.edu
}

known for high enforcement or using in-car radar detection systems. ${ }^{7}$

Automated speed enforcement (ASE) is a promising strategy to address many of the limitations of current approaches to speed enforcement. Evidence from several countries suggests that ASE is an effective and cost-effective strategy for reducing traffic-related injuries. However, ASE use in the USA remains comparatively limited. In this article, we summarise the evidence on ASE, describe the current state of domestic ASE implementation and identify future research areas and policy strategies to support expanded ASE implementation to improve road safety.

\section{SPEED CONTROL: ASSESSING THE EVIDENCE FOR ASE}

The most common ASE technologies rely on speed cameras, which are activated when a driver exceeds the specified limit. ASE technology is also used for average speed enforcement using interval-based systems, which measure the vehicle's average speed between two sites and issue citations if that average exceeds the legal posted limit. In both applications, citations are generally mailed to the vehicle owner, identifying the date, location and speed of the vehicle.

ASE systems offer several advantages over traditional enforcement. As ASE does not require the presence of an officer, it can continuously enforce the speed limit and can do so at lower cost. ASE systems also enable enforcement in congested areas or where enforcement is otherwise dangerous or infeasible and can reduce congestion from driver distraction at traffic stops (ie, 'rubbernecking'). They also reduce face-to-face interactions between citizens and police, which may reduce real or perceived issues of racial bias in enforcement. Finally, some technologies, including interval-based cameras, have been shown to reduce the environmental impact from motor vehicles by reducing speed variability, which improves fuel consumption and reduces vehicular emissions. ${ }^{7}$

Empirical research from international settings-and, to a lesser extent, domestic examples-suggests that ASE is a promising mechanism to improve traffic safety.
Internationally, studies have demonstrated the effectiveness of ASE in several highincome countries, including UK, Australia, Finland, Norway and France. ${ }^{10}$ For example, a recent study of a nationwide speed enforcement programme introduced in France in 2003 found that ASE implementation was associated with a $21 \%$ reduction in deaths. ${ }^{11}$

A Cochrane review of 35 studies found that ASE systems achieved an 8\%-50\% reduction in injury crashes in the camera vicinity and an 11\%-44\% reduction in fatal or serious injuries. ${ }^{12}$ While costeffectiveness data are limited, studies suggest that ASE can also be remarkably cost effective, with benefit-cost ratios potentially exceeding 10:1. ${ }^{13-15}$ For example, a 2005 study of British Columbia's ASE system estimated an annual net benefit of US\$88 million, due primarily to reductions in crashes resulting in injury or fatality. ${ }^{15}$

While domestic ASE use has been limited, preliminary evidence from US programmes suggests potential safety benefits. ASE programmes have demonstrated effectiveness in reducing speeds in both lowspeed settings, such as school zones or residential areas, ${ }^{16} 17$ and high-speed settings, such as highways. ${ }^{17} 18$ Additional evidence indicates that ASE systems may have a 'spillover effect,' achieving reductions in speeds on neighbouring roads, suggesting that ASE may promote community-wide changes in driver behaviour. ${ }^{16}$ Early results from domestic programmes suggests that ASE may also reduce traffic-related injuries, with four short-term evaluations estimating reductions in total crashes and injury crashes ranging from $0 \%$ to $55 \%$ and $28 \%$ to $48 \%$, respectively. ${ }^{19-22}$

\section{DOMESTIC USE OF ASE}

In the USA, leading national organisations have publicly supported ASE systems, including the Department of Transportation, the Insurance Institute for Highway Safety and the American Association of State Highway and Transportation Officials. As of April 2015, speed cameras were in use in 134 communities across the USA. ${ }^{23}$ Local governments have been important innovators in ASE programmes, experimenting with novel approaches and tailoring programmes to fit the particular needs of their communities. However, the regulatory authority of municipal and county governments is defined-and in some cases, constrained-by state law. Cities or counties cannot implement ASE systems or otherwise enforce laws that are not authorised by or that conflict with state law. Consequently, state laws play an important role in ASE implementation. 
To date, states have taken a range of legislative approaches towards ASE. ${ }^{24}$ Table 1 summarises state laws pertaining to ASE. At the restrictive end of the spectrum, 13 states have enacted laws that either expressly prohibit ASE outright or establish restrictions that effectively prevent their use, such as requiring the presence of an officer at the ASE site or that a citation be issued at the time of offense-considerably reducing the feasibility and costeffectiveness of ASE programmes. At the other end of the spectrum, nine states and DC have laws that either explicitly permit the use of cameras or that impose fairly minimal restrictions on their use, such as limiting ASE to specific settings such as school or construction zones, or residential areas. In the remaining 28 states, no laws specifically address ASE.

\section{UNDERSTANDING THE IMPLEMENTATION GAP}

If ASE systems could reduce traffic-related injuries, why has the USA been relatively slow to expand their use? Several hypotheses have been proposed to explain the gap between evidence and action on ASE.

\section{Public acceptability of ASE systems}

Automated enforcement is perceived to be a highly politicised issue, spawning vigorous debate among citizens and policymakers alike. ${ }^{8} 25$ Media coverage of current ASE programmes has also shown the spotlight on issues with ASE implementation. For example, several reports have identified technological failures, including a Chicago driver who received a warning for going 37 miles per hour (mph), despite her car being parked at the time of the offense. ${ }^{26}$ Such technological failures raise questions for the fairness and enforceability of ASE.

Additional critiques challenge the underlying motivations for ASE programmes, with many perceiving that ASE are being used to raise revenue, rather than promote safety. ${ }^{27}$ These criticisms find particular resonance among a broader debate on the over-reliance of municipalities on petty fines and fees to fund city services and the disproportionate burden of these fines on minorities. Such concerns may be heightened when private contractors administer ASE programmes and receive a portion of resultant fines, which creates a conflict of interest between the duty to administer programmes fairly against the secondary interest of generating revenue. ASE has also raised privacy concerns, including that cameras exacerbate a 'Big Brother' culture or may be used for purposes other than reducing speeds. ${ }^{8}$ Finally, some individuals have expressed opposition to automated systems, preferring to have in-person contact with the citing officer so as to explain circumstances related to the violation. ${ }^{8}$

Data on the domestic public acceptability of ASE are limited. Nevertheless, public opinion research suggests that ASE may be more complex than the media portrayals might suggest.

A systematic review of public opinion research on motor vehicle-related injuries from 2003 to 2013 identified only four studies that examined public attitudes towards ASE systems. ${ }^{28}$ Of these studies, two used a national sample ${ }^{25} 29$ and two assessed attitudes in local jurisdictions. ${ }^{16} 18$ In general, these studies found moderate to strong support among the public for ASE, suggesting that ASE opposition may be driven by a vocal minority, rather than reflect broad resistance.

However, these and more recent studies also indicate that support may be highly contingent upon specific implementation features. Considerable support exists for focusing upon 'high-risk drivers', such as those going $\geq 20 \mathrm{mph}$ over posted speed limits. ${ }^{29}$ Support is also high for ASE in certain areas, including in school zones $(85 \%-87 \%)$ on roads with heavy speeding $(75 \%)$ or a history of crashes $(81 \%-84 \%)$, or to target areas where traditional enforcement is infeasible or dangerous due to congestion or other road conditions $(69 \%-70 \%) .^{25} 2729$ Support is considerably lower for the use of ASE systems on all roads $(35 \%-43 \%){ }^{25} 27$

Furthermore, the strength of support for ASE systems is less robust than for other evidence-based measures to reduce traffic-related injuries. A 2011 study found that only $29 \%$ of Americans strongly favour ASE, only half the proportion who strongly support other evidence-based policies, including mandatory motorcycle helmet use, graduated drivers license programmes, sobriety checkpoints and breathalyzer-based ignition locks. ${ }^{25}$ Similarly, a 2013 study found that support for photo enforcement was weaker than

Table 1 State laws pertaining to automated speed enforcement

\begin{tabular}{|c|c|c|c|c|}
\hline $\begin{array}{l}\text { Enabling legislation } \\
\text { exists for ASE }\end{array}$ & Legislation restricts/limits ASE & $\begin{array}{l}\text { Legislation expressly or } \\
\text { effectively prohibits ASE }\end{array}$ & No ASE legislation & \\
\hline Arizona & Colorado & Arkansas & Alabama & Michigan \\
\hline$D C$ & Illinois & Maine & Alaska & Minnesota \\
\hline \multirow[t]{12}{*}{ Tennessee } & Louisiana & Mississippi & California & Missourit \\
\hline & Maryland & Montana & Connecticut & Nebraska \\
\hline & New York & Nevada & Delaware & New Mexico \\
\hline & Oregon & New Hampshire & Florida & North Carolina \\
\hline & Washington & New Jersey & Georgia & North Dakota \\
\hline & & Ohio* & Hawaii & Oklahoma \\
\hline & & South Carolina & Idaho & Pennsylvania \\
\hline & & Texas & Indiana & Rhode Island \\
\hline & & Utah & lowat & South Dakota \\
\hline & & West Virginia & Kansas & Vermont \\
\hline & & Wisconsin & Kentucky & Virginia \\
\hline & & & Massachusetts & Wyoming \\
\hline
\end{tabular}

*Ohio passed a new law in December 2014, effective March 2015, that will require the presence of an officer at the time of citation. While the cameras had been in use in several municipalities before the law, it is anticipated that the law will end the use of speed cameras across the state.

tNo state law, but programmes operating under local ordinance or DOT supervision.

¥New Mexico's Department of Transportation has banned the use of ASE on state and federal roads, but no state legislation exists to permit or prohibit ASE use.

${ }^{5}$ Information in this table modified from data compiled by the Governors Highway Safety Administration. ${ }^{24}$

ASE, automated speed enforcement. 
that for other traffic safety measures, suggesting that speed control may not be a high-priority issue for most Americans, and thus may be correspondingly lower on the policymaking agenda. ${ }^{30}$ A 2014 study in Washington, DC, however, found that $43.4 \%$ of residents strongly supported ASE, indicating that support may be stronger within some local jurisdictions. ${ }^{31}$

Related to the issue of lack of broad public support for ASE is the lack of awareness among the public about traffic safety successes. A study of public perceptions of the effectiveness of evidencebased countermeasures found large gaps in the public's appreciation of the effectiveness of certain policies such as raising the minimum legal drinking age and corresponding reductions in alcohol-related MVCs. ${ }^{32}$ These findings suggest that injury professionals should be more proactive in sharing their research findings with both the public and the policymakers. To that end, Smith $e t a l^{33}$ found that when the public was informed about the evidence base for selected traffic safety policies, support increased. Although neither study focused on ASE systems, both provide encouragement for generating increased public support.

\section{Coordination challenges}

Additionally, development and implementation of ASE systems require coordination across a range of actors. Public health researchers can play a critical scientific role in bringing the analytical tools and preventative perspective to ASE systems development. $^{34}$ However, public health researchers need partners to mount a successful ASE system. On the operational side, key partners include the agency or department that will lead implementation, such as a police department or department of transportation, as well as others involved in planning and operations, including the department of motor vehicles or relevant elected officials such as the city council-all of whom face competing demands on their time and resources. ${ }^{35}$ ASE systems also require extensive public education to inform the public of key details about the programme and its motive to improve safety, including the location of cameras, the use of revenue and the results of programme evaluations. Finally, and perhaps most significantly, ASE systems only target enforcement of existing speed limits. Large-scale reductions in speed-related traffic injuries will likely only occur within the context of a broader traffic safety programme, including lowering existing speed limits.

\section{FUTURE RESEARCH AND POLICY AGENDA}

The use of ASE systems for speed regulation is a promising strategy for preventing speed-related traffic injuries. However, additional research is needed to identify when, and in what circumstances, ASE systems can support reductions in speed-related traffic injuries, as well as to identify successful policy-making approaches to support their use. Following Vernick, ${ }^{36}$ we believe that the ideal process is iterative, with evaluations used to refine policies and support further enactment. In what follows, we identify three research areas to facilitate expanded use of ASE systems.

\section{Policy evaluation studies}

First, additional empirical research is needed to identify whether, and in what circumstances, ASE systems successfully reduce both speed and traffic-related injuries. While prior studies suggest that ASE systems are effective, the quality of such studies is mixed, with considerable variation in the duration of follow-up and the use of comparison groups or appropriate controls for potential confounders. Consequently, systematic reviews of ASE system effectiveness have found considerable heterogeneity in effectiveness, with reductions in collisions and injuries ranging from $14 \%$ to $72 \%$ and $8 \%$ to $46 \%$, respectively. ${ }^{10}{ }^{12}$ Future research should take advantage of natural experiments, comparing trends in speed-related crashes, injuries and deaths across states with different policies and implementation experiences to identify the potentially relevant features of ASE systems and to explore which characteristics are associated with greater effectiveness.

In addition to their vital role in supporting ASE effectiveness, such studies can also play a strategical function for future policymaking. Quantifying the lives saved from ASE systems can play a powerful role in shaping the policy landscape, providing a measurement of the existing problem that can draw attention to an issue and create pressure upon policymakers to move it further up the political agenda.

\section{Public opinion research}

Second, while demonstrating effectiveness is a critical step, subsequent research will be needed to translate evidence-based programmes into public policies. Public opinion data can play a key role in this translation, identifying public priorities and enabling legislators to craft policies that can secure buy-in from the public and key stakeholders.
Existing public opinion data on ASE systems may be instructive regarding the features of ASE systems that shape support. For example, previous research suggests that public opinion for ASE is highly contingent upon specific implementation features, such as the level of the fine imposed, the type of road on which it is used and the speed at which a penalty is triggered. ${ }^{26} 29$ Understanding how these features impact support can enable policymakers to strategically tailor policies to minimise opposition and support the development of an incremental approach to ASE implementation, such as first introducing cameras in residential areas, before expanding to highway use.

Future public opinion research could explore the effects of framing upon support for ASE systems. For example, survey experiments could test the influence of loss versus gain frames (eg, risk of death without ASE vs potential lives saved with ASE). Additional survey experiments could assess the relative effectiveness of different justifications for ASE use, such as revenue generation versus safety improvements. Given evidence that drivers are more likely to perceive that ASE systems are used to generate revenue, rather than to promote safety, ${ }^{27}$ information on the effect of these justifications may prove critical for shaping communication strategies and programmatic efforts to garner support for ASE legislation.

\section{Policymaking and implementation studies}

Finally, further research is needed to understand the policymaking process and implementation issues associated with automated enforcement. Strong enabling legislation for ASE systems has been identified as among the most critical components of a successful speed camera programme. ${ }^{37}$ Consequently, there is a critical need for policymaking studies to identify the factors that encourage or dissuade policymakers to initiate policy activity for ASE. ${ }^{38}$ Interview studies or surveys of public officials and their staff can provide critical insight into why state legislatures pass enabling or inhibiting legislation for speed cameras. For example, a 1993 study of Colorado state legislators found that legislators who considered restrictions on individual freedom an 'extremely' important voting criterion were 43 times more likely to oppose a proposed seat belt law. ${ }^{39}$ Econometrical analyses could provide an additional mechanism for understanding the policymaking process, enabling researchers to examine the extent to which observable characteristics of a state or local government predict 
the likelihood that a specific law passed or programme initiated. ${ }^{38}$ This research offers the potential to identify 'friendly' venues for policy experimentation, such as identifying states without existing legislation that may be more receptive to policy experimentation.

Enabling legislation, however, is only the first step. For an ASE system to be effective, it must be implemented so as to actually influence driver behaviour. The National Highway Traffic Safety Administration has published operational guidelines to assist in the planning and implementation of ASE programmes. ${ }^{35}$ While these guidelines draw on domestic evidence where available, some recommendations reflect experiences from international contexts, which may not necessarily capture features relevant to the US context. Additional research is therefore needed to examine how the 'law on the books' is translated into ASE systems within US communities. Implementation studies can also play a key role in tracing this process, identifying how laws for ASE systems are implemented and enforced. ${ }^{38}$ For example, case studies of ASE policy efforts or interviews with local officials or transportation authorities to explore barriers and enablers of successful policies could help to identify best strategies for future policy adoption and implementation. ${ }^{40}$

\section{CONCLUSION}

The demonstrated success of ASE systems in other countries indicates ASE is currently a missed opportunity for the USA. However, interventions proven effective in one setting may not be easily transferable elsewhere. Further research will be needed to determine the conditions under which ASE systems can be deployed effectively to reduce traffic-related injuries in the USA. The substantial burden of these injuries, and the corresponding potential of ASE systems to reduce this burden, should motivate further demonstration projects in the domestic setting.

Twitter Follow Stephanie Morain at @smorain

Acknowledgements Dr Morain is grateful to the Hecht-Levi Fellowship programme in Bioethics at the Johns Hopkins Berman Institute of Bioethics for valuable institutional and collegial support.

Contributors All authors contributed to the conception and design of the paper. SRM wrote the first draft, and all authors revised it critically for intellectual content. All authors gave approval of the final version.

Funding Dr Morain's effort on this project was graciously supported by the Hecht-Levi Postdoctoral Program at the Berman Institute for Bioethics.

Competing interests None declared.
Provenance and peer review Not commissioned; externally peer reviewed.
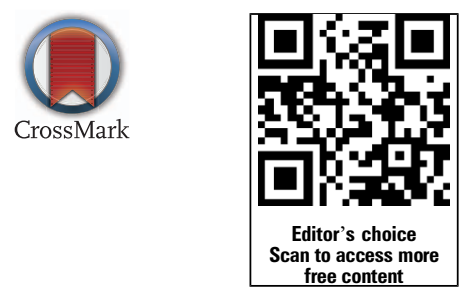

To cite Morain SR, Gielen AC, Bhalla K. Inj Prev 2016;22:79-83.

Received 7 December 2014

Revised 21 April 2015

Accepted 29 April 2015

Published Online First 25 May 2015

Inj Prev 2016:22:79-83.

doi:10.1136/injuryprev-2014-041507

\section{REFERENCES}

1 National Highway Traffic Safety Administration. Traffic Safety Facts: 2012 Data Overview. Revised May 2014. http://www-nrd.nhtsa.dot.gov/Pubs/812016. pdf (accessed Nov 2014).

2 Centers for Disease Control and Prevention, National Center for Injury Prevention and Control. Web-based Injury Statistics Query and Reporting System (WISQARS) 2011. http://www.cdc.gov/injury/wisqars (accessed Nov 2014).

3 Naumann R, Dellinger A, Zaloshnja E, et al. Incidence and total lifetime costs of motor vehicle-related fatal and nonfatal injury by road user type, United States, 2005. Traffic Inj Prev 2010;11:353-60.

4 Bhalla K, Shotten M, Cohen A, et al. Transport for health: the global burden of disease due to injuries and air pollution from motorized road transport. Washington, DC: World Bank Global Road Safety Facility, and Institute for Health Metrics and Evaluation 2014. http://www. healthmetricsandevaluation.org/gbd/publications/ policy-report/transport-health-global-burden-diseasemotorized-road-transport (accessed Nov 2014).

5 Kelley B. It is speed that kills. J Public Health Policy 2005;26:416-17

6 Deangelo $G$, Hansen $B$. Life and death in the fast lane: police enforcement and traffic fatalities. Am Econ J Econ Pol 2014;6:231-57.

7 Soole DW, Watson BC, Fleiter JJ. Effects of average speed enforcement on speed compliance and crashes: a review of the literature. Accid Anal Prev 2013;54:46-56.

8 Delaney A, Ward H, Cameron M. Controversies and speed cameras: lessons learnt internationally. J Public Health Policy 2005;26:404-15.

9 Lundman RJ, Kaufman RL. Driving while black: effects of race, ethnicity, and gender on citizen selfreports of traffic stops and police actions. Criminology 2003;94:309-50.

10 Thomas LJ, Srinrivasan R, Decina LE, et al. Safety effects of automated speed enforcement programs: critical review of international literature. Trans Res Rec 2008;2078:117-26.

11 Carnis LL, Blais EE. An assessment of the safety effects of the French speed camera program. Accid Anal Prev 2013;51:301-9.

12 Wilson CC, Willis JK, Hendrikz, et al. Speed enforcement detection devices for preventing road traffic injuries (Review). Cochrane Database Syst Rev 2006;2:CD004607.

13 Elvik R. Effects on accidents of automated speed enforcement in Norway. Transp Res Rec 1997;1595:14-19.
14 Cameron MH, Delaney AK. Speed EnforcementEffects, Mechanisms, Intensity and Economic Benefits of Each Mode of Operation. Presentation to Joint Australasian College of Road Safety and Queensland Parliamentary Travelsafe Committee conference "High Risk Road Users-Motivating behaviour change: what works and what doesn't work?" Parliament House, Brisbane, 18-19 September 2008. http:// www.monash.edu.au/miri/research/reports/papers/ 2008-cameron-speed.pdf (accessed Nov 2014).

15 Chen G. Safety and economic impacts of photo radar program. Traffic Inj Prev 2005;6:299-307.

16 Retting RA, McCartt AT, Farmer CM. Evaluation of automated speed enforcement in montgomery county, Maryland. Traffic Inj Prev 2008;9:440-5.

17 Retting RA, Farmer CM. Evaluation of speed camera enforcement in the District of Columbia. Transp Res Rec 2003;1830:34-7.

18 Retting RA, Kyrychenko SY, McCartt AT. Evaluation of automated speed enforcement on Loop 101 freeway in Scottsdale, Arizona. Accid Anal Prev 2008; 40:1506-12.

19 Skubic J, Johnson SB, Salvino C, et al. Do speed cameras reduce collisions? Ann Adv Automov Med 2013;57:365.

20 Skubic J, Vanhoy S, Chengcheng P, et al. Impact of speed cameras on trauma centers. J Trauma Acute Care Surg 2014;77:193-7.

21 Cunningham CM, Hummer JE, Moon J. Analysis of automated speed enforcement cameras in Charlotte, North Carolina. Transp Res Rec 2008;2978: 127-34.

22 Shin K, Washington SP, Schalkwyk I. Evaluation of the Scottsdale Loop 101 automated speed enforcement demonstration program. Accid Anal Prev 2009;41:393-403.

23 Insurance Institute for Highway Safety. Automated Enforcement: April 2015. http://www.iihs.org/iihs/topics/ laws/automated_enforcement (accessed Apr 2015).

24 Governors Highway Safety Administration. Speed and Red light Camera Laws: November 2014. http:/l www.ghsa.org/html/stateinfo/laws/auto_enforce.html (accessed Nov 2014).

25 Munnich LW, Loveland JD. Do Americans oppose controversial evidence-based road safety policies? Transp Res Rec 2011;2213:9-12.

26 Ruthhart B, Hirst EJ. Speed camera system flags a parked car. Chicago Tribune, November 28, 2013 http://articles.chicagotribune.com/2013-11-28/news/ ct-speed-camera-parked-car-met-20131128_1_ camera-american-traffic-solutions-warning (accessed Nov 2014).

27 National Highway Traffic Safety Administration. National Survey of Speeding and Unsafe Driving Attitudes and Behavior 2011. Washington DC: NHTSA. DOT HS 811865.

28 Debinski B, Smith KC, Gielen A. Public opinion on motor vehicle-related injury prevention policies: a systematic review of a decade of research. Traffic Inj Prev 2014;15:243-51.

29 National Highway Traffic Safety Administration. National Survey of Speeding and Unsafe Driving Attitudes and Behavior 2003. Washington DC: NHTSA. DOT HS 809730.

30 Girasek DC. Gauging popular support for traffic safety in the United States. Accid Anal Prev 2013;50:1112-17.

31 Cicchino JB, Wells JK, McCartt AT. Survey about pedestrian safety and attitudes toward automated traffic enforcement in Washington, D.C. Traffic Inj Prev 2014;15:414-23.

32 Girasek DC, Gielen AC, The effectiveness of injury prevention strategies: what does the public believe? Health Educ Behav 2003;30:287-304.

33 Smith KC, Debinski B, Pollack K, et al. Researchinformed evidence and support for road safety legislation: Findings from a national survey. Accid Anal Prev 2014;73:109-15. 
34 Bonnie RJ, Guyer B. Injury as a field of public health: achievements and controversies. J Law Med Ethics 2002;30:267-80.

35 National Highway Traffic Safety Administration. Speed Enforcement Camera Systems Operational Guidelines. 2008. Washington, DC: NHTSA. DOT HS 810916.

36 Vernick JS. Injury prevention policy forum. Inj Prev 2006:12:382-4.
37 National Cooperative Highway Research Program. Automated Enforcement for Speeding and Red Light Running 2012. Report 729. http://onlinepubs.trb.org/ onlinepubs/nchrp/nchrp_rpt_729.pdf (accessed Nov 2014).

38 Burris S, Wagenaar AC, Swanson J, et al. Making the case for laws that improve health: a framework for public health law research. Milbank Q 2010;88: 169-210.
39 Lowenstein SR, Koziol-McLain J, Satterfield G, et al. Facts versus values: why legislators vote against injury control laws. J Trauma Acute Care Surg 1993;35:786.

40 Brussoni $M$, Towner $E$, Hayes $M$. Evidence into practice: combining the art and science of injury prevention. Inj Prev 2006;12:373-7.

\section{Philippine injury reduction campaign}

The Department of Health (DOH) in one Health region in the Philippines launched an Injury Reduction (APIR) campaign to remind the public against using firecrackers and pyrotechnics to prevent injuries. The DOH recorded 249 firecracker injuries in 2014 resulting in many eye injuries and some blast injuries that needed amputation.

\section{Preventing falls in seniors}

A health network in Northern Ontario, Canada, has launched a public awareness campaign to help seniors prevent life-threatening falls - the main reason older adults lose their independence. The intention is to use a television and poster campaign. Stay on Your Feet (SOYF) is a fall prevention strategy that includes physical activity opportunities (free exercise and Stand Up classes). 